\title{
Functional imaging of multidrug resistance in an orthotopic model of osteosarcoma using ${ }^{99 m}$ Tc-sestamibi
}

\author{
Célia M. F. Gomes • Mick Welling • Ivo Que • \\ Niek V. Henriquez • Gabri van der Pluijm • \\ Salvatore Romeo • Antero J. Abrunhosa • \\ M. Filomena Botelho • Pancras C. W. Hogendoorn • \\ Ernest K. J. Pauwels • Anne Marie Cleton-Jansen
}

Received: 27 December 2006 / Accepted: 16 April 2007 / Published online: 1 June 2007

(C) Springer-Verlag 2007

\begin{abstract}
Purpose The purpose of this work was the development of an orthotopic model of osteosarcoma based on luciferaseexpressing tumour cells for the in vivo imaging of multidrug resistance (MDR) with ${ }^{99 \mathrm{~m}} \mathrm{Tc}$-sestamibi.

Methods Doxorubicin-sensitive (143B-luc ${ }^{+}$) and resistant $\left(\mathrm{MNNG} / \mathrm{HOS}-\mathrm{luc}^{+}\right.$) osteosarcoma cell lines expressing different levels of P-glycoprotein and carrying a luciferase reporter gene were inoculated into the tibia of nude mice. Local tumour growth was monitored weekly by bioluminescence imaging and X-ray. After tumour growth, a ${ }^{99 \mathrm{~m}} \mathrm{Tc}$ sestamibi dynamic study was performed. A subset of animals was pre-treated with an MDR inhibitor (PSC833). Images were analysed for calculation of ${ }^{99 \mathrm{~m}} \mathrm{Tc}$-sestamibi washout half-life $\left(t_{1 / 2}\right)$, percentage washout rate $(\% \mathrm{WR})$ and tumour/non-tumour (T/NT) ratio.
\end{abstract}

C. M. F. Gomes $\cdot$ M. Welling • E. K. J. Pauwels

Department of Radiology, Section of Nuclear Medicine,

Leiden University Medical Center,

Leiden, The Netherlands

S. Romeo • P. C. W. Hogendoorn · A. M. Cleton-Jansen Department of Pathology, Leiden University Medical Center,

Leiden, The Netherlands

I. Que · N. V. Henriquez • G. van der Pluijm

Department of Endocrinology, Leiden University Medical Center,

Leiden, The Netherlands

C. M. F. Gomes $(\square) \cdot$ A. J. Abrunhosa • M. F. Botelho

IBILI - Faculty of Medicine,

Institute of Biophysics/Biomathematics,

Az. de Sta. Comba, Celas,

3000-354 Coimbra, Portugal

e-mail: cgomes@ibili.uc.pt
Results A progressively increasing bioluminescent signal was detected in the proximal tibia after 2 weeks. The $t_{1 / 2}$ of ${ }^{99 \mathrm{~m}} \mathrm{Tc}$-sestamibi was significantly shorter $(p<0.05)$ in drugresistant $\mathrm{MNNG} / \mathrm{HOS}-\mathrm{luc}^{+}$tumours $\left(t_{1 / 2}=87.3 \pm 15.7 \mathrm{~min}\right)$ than in drug-sensitive 143B-luc ${ }^{+}$tumours $\left(t_{1 / 2}=161.0 \pm 47.4\right.$ $\min )$ and decreased significantly with PSC833 $\left(t_{1 / 2}=173.0 \pm\right.$ $24.5 \mathrm{~min}, p<0.05$ ). No significant effects of PSC833 were observed in 143B-luc ${ }^{+}$tumours. The T/NT ratio was significantly lower $(p<0.05)$ in MNNG/HOS-luc ${ }^{+}$tumours than in $143 \mathrm{~B}-$ luc $^{+}$tumours at early $(1.55 \pm 0.22$ vs $2.14 \pm$ $0.36)$ and delayed times $(1.12 \pm 0.11$ vs $1.62 \pm 0.33)$. PSC 833 had no significant effects on the T/NT ratios of either tumour.

Conclusion The orthotopic injection of tumour cells provides an animal model suitable for functional imaging of MDR. In vivo bioluminescence imaging allows the non-invasive monitoring of tumour growth. The kinetic analysis of ${ }^{99} \mathrm{~m}$ Tc-sestamibi washout provides information on the functional activity of MDR related to P-glycoprotein expression and its pharmacological inhibition in osteosarcoma.

Keywords Osteosarcoma - Orthotopic model . Bioluminescence $\cdot$ Multidrug resistance $\cdot{ }^{99 \mathrm{~m}} \mathrm{Tc}$-sestamibi

\section{Introduction}

Osteosarcoma (OS) is the most common primary malignant bone tumour and occurs most frequently in children and adolescents. Advances in treatments, including multiagent chemotherapy regimens, have increased considerably the long-term disease-free survival rates, up to $50-80 \%$ [1-4]. However, $25-50 \%$ of patients without evidence of metastasis at diagnosis subsequently develop systemic disease, 
mostly related to poor response to chemotherapy [2-4]. So far, the histological response to pre-operative neoadjuvant chemotherapy based on the Huvos grading system is the sole reliable predictive parameter for survival in non-metastatic OS [1-3, 5]. Nevertheless, this prognostic marker is ineffective in altering the outcome of poor responders, and no survival benefit has been demonstrated with the increase in drug dosage in histological poor responders [5-7]. Moreover, it was recently shown that histological response but not survival improved in OS patients treated with intensified chemotherapy [8]. Distant tumour relapses in OS are likely to be, at least partly, due to drug resistance. Multidrug resistance (MDR) to chemotherapy is associated with a myriad of mechanisms that decrease drug cytotoxicity in tumour cells. The most common involves an increased efflux of a broad range of hydrophobic cytotoxic drugs, mediated by the overexpression of ATP-binding cassette (ABC) transporters, such as P-glycoprotein (Pgp), multidrug resistance-associated protein-1 (MRP1) and breast cancerrelated protein (BCRP) [9-11].

In vitro and clinical observations have shown that the overexpression of Pgp at the time of diagnosis is associated with drug resistance, tumour recurrence and poor outcome in OS patients, suggesting that Pgp overexpression could be used as a prognostic factor [12-14]. However, other studies have failed to confirm this relationship and the role of Pgp as a prognostic marker remains controversial $[15,16]$. This controversy could partly be attributed to substantial methodological differences between studies with respect to tissue collection methodologies, molecular targets (mRNA versus protein) and the timing of Pgp assessment (pre-chemotherapy or post-chemotherapy). Furthermore, common chemotherapeutic regimens in OS include doxorubicin, a substrate of Pgp, but also methotrexate and cisplatin, which are substrates for other MDR transporters acting independently of Pgp.

${ }^{99 \mathrm{~m}} \mathrm{Tc}$-sestamibi, a tumour-seeking agent, has been recognised as a substrate for Pgp and MRP1 [17-19]. Several studies have reported that absence or reduced uptake of ${ }^{99 \mathrm{~m}} \mathrm{Tc}$-sestamibi may serve to predict poor response to therapy in several human malignant tumours, including lymphoma, lung cancer and breast cancer [17, 20-22].

To date, only a few clinical studies have been published on the prognostic value of ${ }^{99 \mathrm{~m}} \mathrm{Tc}$-sestamibi imaging in OS, and its relevance in predicting tumour response remains unclear. Burak et al. [23, 24] found a significant correlation between the washout rate of ${ }^{99 \mathrm{~m}} \mathrm{Tc}$-sestamibi and both Pgp and MRP1 expression in OS patients, whereas Gorlick et al. [25] could not identify a significant correlation between ${ }^{99 \mathrm{~m}} \mathrm{Tc}$-sestamibi scintigraphic parameters and measurements of Pgp expression or histological necrosis in highgrade OS patients. The limited number of cases studied together with the absence of standardised criteria and a reliable index reflecting the Pgp-mediated outward trans- port can explain these discrepancies. Furthermore, other $\mathrm{ABC}$ transporters such as MRP1 and BCRP can confer drug resistance $[26,27]$ and have not been extensively studied in OS.

Previous results obtained by our group showed that human OS cell lines, not previously selected for drug resistance, display different expression patterns of MDRassociated transporters (Pgp, MRP1 and BCRP) [28]. Studies on chemosensitivity to drugs used in the recently started EURAMOS protocol (doxorubicin, cisplatin and methotrexate) revealed that chemosensitivity to doxorubicin is strongly dependent on Pgp expression, which can be circumvented by addition of cyclosporine $\mathrm{A}$, a potent inhibitor of Pgp. Moreover, both uptake and efflux kinetics of ${ }^{99 m} \mathrm{Tc}$-sestamibi were significantly correlated with Pgp expression and sensitivity to doxorubicin [28].

These results led us to investigate the ability of functional imaging using ${ }^{99 \mathrm{~m}} \mathrm{Tc}$-sestamibi to identify Pgp-mediated drug resistance in animal models of OS. Most in vivo studies have been performed in animal models with subcutaneous tumours. These models cannot reproduce the pathophysiological basis for tumour growth and lack the influence of the specific organ microenvironment on the biological behaviour of tumour cells. The orthotopic implantation of tumour cells in the tibia or femur of mice results in a primary tumour growth consistent with OS [29]. Cancer cell lines stably transfected either with the firefly luciferase (Luc) or the green fluorescent protein (GFP) have been used to monitor in living mice the local tumour growth and the development of metastasis to different organs $[30,31]$.

In this study we developed an orthotopic model of human OS based on luciferase-expressing OS cells with different chemosensitivity for in vivo imaging of MDR and pharmacological inhibition using ${ }^{99 \mathrm{~m}} \mathrm{Tc}$-sestamibi. Local tumour growth was monitored by whole-body bioluminescence imaging (BLI).

\section{Materials and methods}

Cell culture and transfection

Human OS cell lines MNNG/HOS and 143B were purchased from the American Type Culture Collection (ATCC; Rockville, MD, USA). Both MNNG/HOS and 143B are derived from the same cell line (TE85) but MNNG/HOS resulted from pre-treatment $N$-methyl- $N$-nitro- $N$-nitroguanidine (MNNG) and 143B was virus transformed. This accounts for their differences in proliferation and drug resistance profiles [28, 32].

In previous work, we demonstrated that MNNG/HOS is a doxorubicin-resistant Pgp-expressing cell line, whereas 
143B expresses lower levels of Pgp and is sensitive to doxorubicin [28]. Measurements of Pgp mRNA expression levels by quantitative reverse transcriptase polymerase chain reaction show mRNA expression of Ppg in relation to control osteoblasts to be significantly higher $(p<0.01)$ in MNNG/HOS cells $(3.7 \pm 0.34)$ than in $143 \mathrm{~B}$ cells $(2.5 \pm$ 0.20) [28].

Cells were maintained in RPMI 1640 (Gibco, Invitrogen, Life Technologies, Scotland, UK) supplemented with 10\% heat-inactivated foetal calf serum (Gibco) at $37^{\circ} \mathrm{C}$ in a humidified incubator with $5 \% \mathrm{CO}_{2}$.

143B cells were transfected with a cytomegalovirus (CMV) promoter-driven mammalian expression vector for firefly luciferase (CMV-luc) using FuGene (FuGene-6; Roche Biochemicals, Almere, The Netherlands) according to the manufacturer's protocol. CMV-luc was generated by cloning a full-length firefly luciferase cDNA into the pcDNA3.1 plasmid [33] (Invitrogen, Breda, The Netherlands). Owing to a lack of luciferase activity with the CMV-luc construct, MNNG/HOS cells were transfected with the mammalian elongation factor 1-alpha $(\mathrm{EF} 1 \alpha)$. EF1 $\alpha$ was excised as a Hind-III fragment from the pEF-DEST51 vector (Invitrogen) and inserted into pcDNA3.1 after removal of the CMV promoter with $N r u$ I and NheI (Promega GmbH, Mannheim, Germany). Transfected cells were then selected with G418 (0.3 mg/ml, Life Technologies, Basel, Switzerland) and surviving colonies were screened for expression of luciferase activity using the enzymatic assay on lysates (Promega kit). Bioluminescent, G418-resistant cells (143B-luc ${ }^{+}$and MNNG/HOS-luc ${ }^{+}$) were expanded and used for further in vivo whole-body BLI and for scintigraphy with ${ }^{99 m} \mathrm{Tc}-$ sestamibi. All the cell cultures were harvested at subconfluency after being refreshed with medium not containing neomycin $24 \mathrm{~h}$ before animal inoculation.

Animals

Eighteen female nude (BALBc nu/nu) mice, 6-8 weeks old, were purchased from Taconic (Germany N.Y.) and housed under pathogen-free conditions in individual ventilated cages. Sterile food and water were provided ad libitum. All animal studies were performed in compliance with the Dutch laws relating to the conduct of animal experiments and were approved by the local Committee for Animal Experiments.

Orthotopic animal model of osteosarcoma

Mice were anaesthetised by intraperitoneal injection of $50 \mu \mathrm{l}$ of a freshly prepared mixture of ketamine $\mathrm{HCl}$ (100 mg/ml Nimatek, Vetimex Animal Health B.V., Bladel, The Netherlands)/xylazine (2\% Rompun, Bayer AG, Leverkusen, Germany)/PBS ( $\mathrm{pH}=6.8)(1: 1: 1)$. The animal model was established by intraosseous inoculation of cancer cells in the right tibiae as described previously [31]. In brief, two holes, 4-5 $\mathrm{mm}$ apart, were drilled through the bone cortex of the upper right tibia using a $30-\mathrm{G}$ needle. The bone marrow was flushed out with PBS and a single-cell suspension $\left(1 \times 10^{5} / 10 \mu \mathrm{l}\right.$ PBS $)$ was slowly inoculated with a $30-\mathrm{G}$ needle in the upper hole. Finally, the lower and upper holes were sealed with surgical wax and the subcutaneous wound was stitched. Local tumour growth was monitored weekly by BLI and by radiography for formation of osteolytic lesions.

Whole-body bioluminescence imaging

BLI of tumours induced by luciferase-expressing cell lines was performed with the animals under isofluorane anaesthesia $(0.8 \mathrm{~L} / \mathrm{min}$, isofluorane, Air Products, Waddinxveen, The Netherlands) using the XGI-8 gas anaesthesia system (Xenogen). The animals were injected intraperitoneally with D-luciferin sodium salt (Synchem, BHg, Germany) at a dose of $150 \mathrm{mg} / \mathrm{kg}$ body weight and transferred to a lighttight chamber for acquisition of a reference grey-scale body surface images using a Xenogen IVIS 100 imaging system (Xenogen). Five minutes after administration of D-luciferin, photon emission was integrated for a period of $10 \mathrm{~s}$. Greyscale images and bioluminescent images were superimposed and processed using the Living Image (Xenogen Corp, Almeda, CA) and the IGOR software (WaveMetrics Corp, Lake Oswego, OR) for image analysis. The relative light intensity was visualised by pseudocolours. A region of interest (ROI) was drawn over the tumour area for quantification of the bioluminescent signal. Data are presented as cumulative photon counts collected within each ROI (photons $/ \mathrm{s} / \mathrm{cm}^{2} / \mathrm{sr}$ ).

Detection of bone lesions by radiography

The formation of osteolytic lesions was monitored by radiography (Kodac EDR-2 film, Eastman Kodac Co, Rochester, NY) using an X-ray system (Faxitron 43805XR, Hewlett Packard).

Scintigraphic imaging with ${ }^{99 \mathrm{~m}}$ Tc-sestamibi and biodistribution studies

Sestamibi (Bristol-Myers Squibb Medical Imaging, Brussels, Belgium) was reconstituted and radiolabelled with sodium pertechnetate obtained from a freshly eluted ${ }^{99} \mathrm{Mo} /{ }^{99 \mathrm{~m}} \mathrm{Tc}$ generator (Mallinckrodt Medical, Petten, The Netherlands) in saline according to the manufacturer's instructions. Radiolabelling efficiency was always higher than 95\%. A stock solution of the PSC833 (gift from Novartis, Basel, Switzerland) was prepared in ethanol/ 
tween/water (4:1:5) and diluted with saline for intraperitoneal injection of $50 \mathrm{mg} / \mathrm{kg}$ body weight. Half of the animals were treated with PSC833 60 min before injection of ${ }^{99 m} \mathrm{Tc}-$ sestamibi.

PSC833 is a non-immunosuppressive cyclosporine derivative and has been widely reported to be a potent inhibitor of the Pgp transporter in vitro and in vivo [34-37] as well as in clinical trials $[38,39]$. The dosage of PSC 833 was based on previous reports $[36,37]$.

Image acquisition was performed with a single-head gamma camera (Toshiba GCA 7100/UI, Japan) equipped with a low-energy, high-resolution, parallel-hole collimator. Mice were anaesthetised with i.p. injection of $50 \mu \mathrm{l}$ of a mixture of medetomidine $(0.5 \mathrm{mg} / \mathrm{kg}$, Domitor, Pfizer, Espoo, Finland), midazolan ( $5 \mathrm{mg} / \mathrm{kg}$, Dormicum, Roche, Woerden, The Netherlands) and fentanyl $(0.05 \mathrm{mg} / \mathrm{kg})$, and placed on the collimator in a supine position. ${ }^{99 \mathrm{~m}} \mathrm{Tc}$ sestamibi $(10 \mathrm{MBq} / 0.1 \mathrm{ml})$ was slowly administered into the left cardiac ventricle. Immediately thereafter, wholebody dynamic images were acquired every minute for $1 \mathrm{~h}$ (matrix size $128 \times 128$ ).

For image processing, a ROI was drawn on the right leg over the tumour area (T) in the frame showing highest radioactivity and then applied to the entire series of dynamic images. A symmetrical ROI of the same size was set on the contralateral side to determine the radioactivity of the non-tumour area (NT). Tumour to non-tumour ratios (T/NT) were calculated on both early (5 minutes) and delayed images $(60 \mathrm{~min})$. Time-activity curves over the tumour area were generated after decay correction, normalised to the maximum activity and fitted to a monoexponential function by the method of least squares using the Origin software package (OriginLab, Northampton, MA). The washout half-time $\left(t_{1 / 2}\right)$ and the percentage washout rate (\%WR) of ${ }^{99 \mathrm{~m}} \mathrm{Tc}$-sestamibi from the tumour area were calculated as previously described [23, 25].

After imaging acquisition, the animals were sacrificed by cervical dislocation. Tibia containing tumour and samples of blood, heart, skeletal muscle and normal tibia were harvested, weighted and assayed for radioactivity in a well-type sodium iodide $\gamma$-counter (SR3, Nuclear Enterprises, Reading, UK) within the ${ }^{99 \mathrm{~m}}$ Tc-sensitivity energy window set as $20 \%$. Tissue radioactivity was expressed as a percentage of the total dose injected per gram $(\% \mathrm{ID} / \mathrm{g})$.

\section{Histological analysis}

Tumour samples were subsequently fixed in $10 \%$ buffered formalin, decalcified with 10\% EDTA and processed for paraffin embedding. Sections of 4-6 $\mu \mathrm{m}$ were cut and stained with haematoxylin and eosin (H\&E) for histological analysis as previously described $[31,40]$.
Statistical analysis

All data are given as mean \pm SD. Statistical analysis was performed using the unpaired $t$ test for comparisons between two variables within a group or ANOVA for multiple comparisons. $P$ values $<0.05$ were considered statistically significant.

\section{Results}

In vivo monitoring of orthotopic tumour growth

Positive bioluminescent cells, 143B-luc ${ }^{+}$and MNNG/HOS$\mathrm{luc}^{+}$were inoculated directly into the right tibia of nude mice. Local tumour growth was monitored weekly by BLI and by radiography for formation of osteolytic lesions.

Eighty percent of mice inoculated with $143 \mathrm{~B}-\mathrm{luc}^{+}$cells $(n=10)$ developed tumours. Of these, only $50 \%$ showed detectable bioluminescent signals at 2 weeks after inoculation. Figure 1a shows a representative mouse inoculated with $143 \mathrm{~B}-\operatorname{luc}^{+}$cells. A very low signal was registered at the second week, which had increased 28 -fold after 3 weeks and afterwards remained approximately constant (Fig. 1a, Table 1). In contrast, the external tumour volume, measured with a calliper, increased from $70.2 \pm 14.5 \mathrm{~mm}^{3}$ to $106.3 \pm$ $18.4 \mathrm{~mm}^{3}$ between the third and fourth weeks. Due to bone resorption stimulated by tumour cells, tumour progresses and invades the surrounding tissues around the tibia, becoming palpable at 3 weeks.

All mice inoculated with the MNNG/HOS-luc ${ }^{+}$cells $(n=8)$ developed tumours and showed progressive tumour growth indicated by the gradual increase in the bioluminescent signal over time. The first signal was detected 1 week after cell inoculation and thereafter increased substantially, rising 97-fold at 4 weeks (Fig. 1d, Table 1). The external tumour volume, measurable after 3 weeks, increased from $57.5 \pm 20.1$ $\mathrm{mm}^{3}$ to $98.3 \pm 14.5 \mathrm{~mm}^{3}$ between the third and the fourth week. Bioluminescence images clearly demonstrated a difference in the signal intensity between MNNG/HOS-luc ${ }^{+}$ and 143B-luc ${ }^{+}$tumours. The cumulative photon count (photons $/ \mathrm{s} / \mathrm{cm}^{2} / \mathrm{sr}$ ) calculated from the ROI drawn over tumours was markedly higher in MNNG/HOS-luc ${ }^{+}$tumours ( $\sim 30-40$ fold) than in 143B-luc ${ }^{+}$tumours (Table 1).

Radiographs taken at equivalent time points showed initial signs of osteolysis at 3 weeks and these signs became clearly evident at 4 weeks, as illustrated by areas of low mineral content and erosion of the cortical bone for both tumours (Fig. 1b,e).

Histological analysis of both 143B-luc ${ }^{+}$and MNNG/ HOS-luc ${ }^{+}$tumours demonstrated a high-grade sarcoma morphologically consistent with human OS. Representative images are shown in Fig. 1c and f, respectively. 
Fig. 1 Monitoring of orthotopic tumour growth in nude mice. Representative bioluminescent images after intratibial inoculation of 143B-luc ${ }^{+}$cells (a) and MNNG/HOS-luc ${ }^{+}$(d) cells over 4 weeks. Luminescence signal is presented as photons $/ \mathrm{s} / \mathrm{cm}^{2} / \mathrm{sr}$. Radiographs taken at 4 weeks show osteolytic lesions in corresponding 143B-luc ${ }^{+}$(b) and $\mathrm{MNNG} / \mathrm{HOS}-\mathrm{luc}^{+}$(e) tumours. Representative H\&Estained sections of 143B-luc ${ }^{+}$(c) and $\mathrm{MNNG} / \mathrm{HOS}-\mathrm{luc}^{+}$(f) tumours $(40 \times$ original magnification)

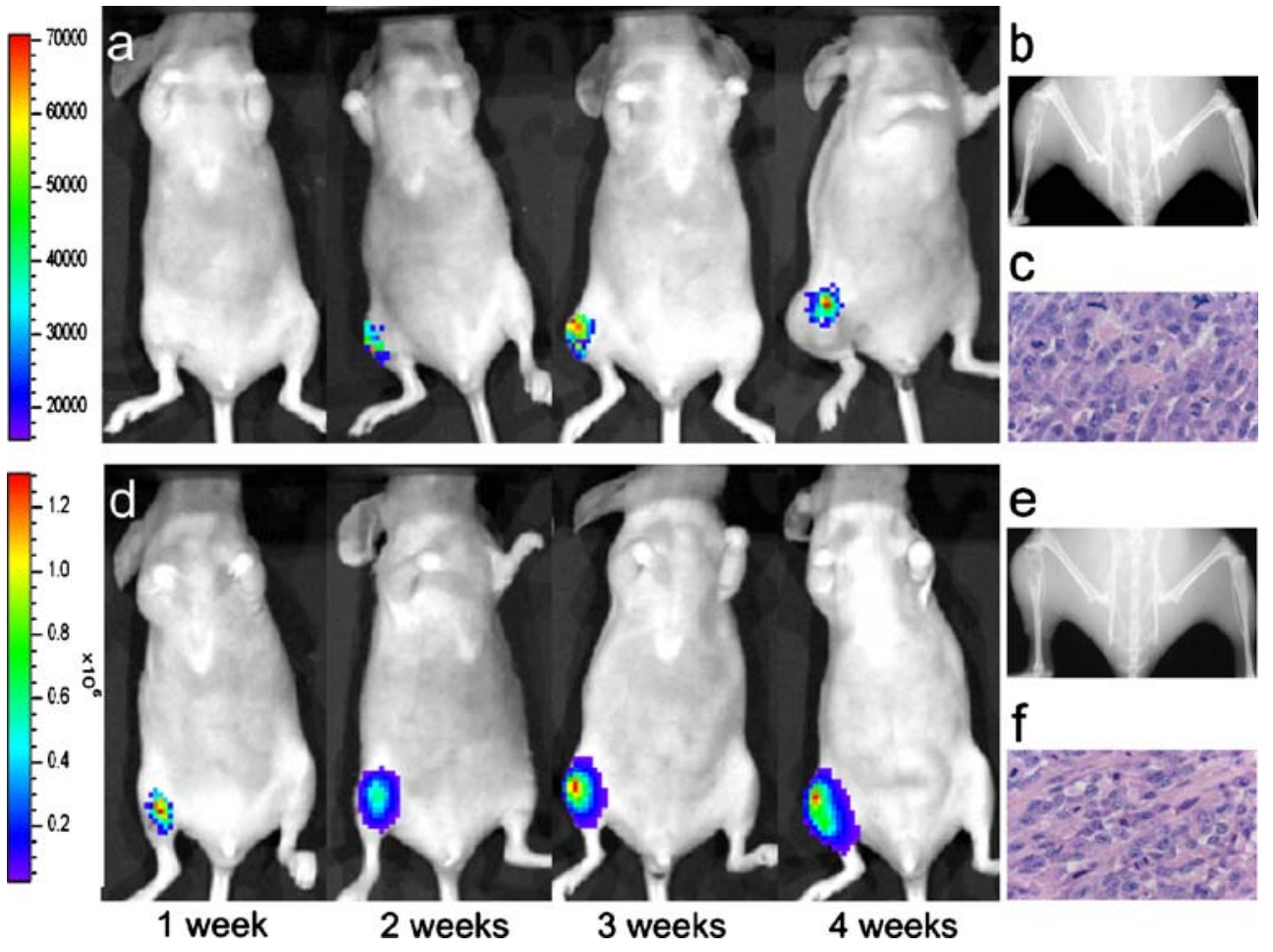

Tumour visualisation with ${ }^{99 \mathrm{~m}} \mathrm{Tc}$-sestamibi

After primary tumour growth, whole-body imaging with ${ }^{99 \mathrm{~m}} \mathrm{Tc}$-sestamibi was performed to assess the functional activity of Pgp in tumours and to evaluate the inhibitor effects of PSC 833 on Pgp activity.

Both 143B-luc ${ }^{+}$and MNNG/HOS-luc ${ }^{+}$tumour-bearing mice were imaged at 4 weeks after cell inoculation. Figure 2 shows representative dynamic images of ${ }^{99 \mathrm{~m}} \mathrm{Tc}$-sestamibi in 143B-luc ${ }^{+}$tumour mice without treatment (a) and after treatment with PSC833 (b). All 143B-luc ${ }^{+}$tumours were clearly visualised at the right tibia within the first $5 \mathrm{~min}$ after injection of ${ }^{99 \mathrm{~m}} \mathrm{Tc}$-sestamibi and remained visible during the 60-min acquisition period, although some activity was washed out from the tumours (Fig. 2a). The images acquired from animals treated with PSC833 $(50 \mathrm{mg} / \mathrm{kg})$ showed an increase in both uptake and retention of ${ }^{99 \mathrm{~m}} \mathrm{Tc}$-sestamibi in 143B-luc ${ }^{+}$tumours (Fig. 2b).

Representative dynamic images from mice with MNNG/ HOS-luc ${ }^{+}$tumours are shown in Fig. 3. The MNNG/HOS$\mathrm{luc}^{+}$tumours were visualised within 1-5 min following injection of ${ }^{99 \mathrm{~m}} \mathrm{Tc}$-sestamibi, but exhibited lower accumulation of ${ }^{99 \mathrm{~m}} \mathrm{Tc}$-sestamibi and less retention of activity compared with 143B-luc ${ }^{+}$tumours (Fig. 3a). Treatment with PSC 833 increased the tumour uptake and substantially decreased the washout rate of ${ }^{99 \mathrm{~m}} \mathrm{Tc}$-sestamibi compared with untreated MNNG/HOS-luc ${ }^{+}$animals (Fig. 3b).

Time-activity curves and kinetic parameters of ${ }^{99 \mathrm{~m}} \mathrm{Tc}$ sestamibi, obtained from imaging analysis, are shown in Fig. 4 and Table 2, respectively. For time-activity curves, the tumour activity was normalised as percentage of peak activity obtained $2-3 \mathrm{~min}$ post-injection. The washout halftimes of ${ }^{99 \mathrm{~m}} \mathrm{Tc}$-sestamibi were significantly $(p<0.05)$ longer in 143B-luc ${ }^{+}$tumours $\left(t_{1 / 2}=161.0 \pm 47.4 \mathrm{~min}\right)$ than in MNNG/HOS-luc ${ }^{+}$tumours $\left(t_{1 / 2}=87.3 \pm 15.7 \mathrm{~min}\right)$. Administration of PSC833 increased significantly $(p<0.05)$ the washout half-times of ${ }^{99 \mathrm{~m}} \mathrm{Tc}$-sestamibi in MNNG/HOS-luc ${ }^{+}$ tumours $\left(\mathrm{t}_{1 / 2}=173.0 \pm 24.5 \mathrm{~min}\right)$ to values comparable to those in 143B-luc ${ }^{+}$tumours. In contrast, no significant effects of PSC833 on the washout half-times of ${ }^{99 \mathrm{~m}} \mathrm{Tc}$ sestamibi in $143 \mathrm{~B}-\operatorname{luc}^{+}$tumours $(p>0.05)$ were observed (Table 2).

Table 1 Progression of bioluminescent signals in MNNG/HOS-luc ${ }^{+}$and 143B-luc ${ }^{+}$tumours growing in tibia of nude mice over 4 weeks

\begin{tabular}{|c|c|c|c|c|}
\hline \multirow[t]{2}{*}{ Tumour } & \multicolumn{4}{|c|}{ Bioluminescent signal $\left(\mathrm{p} / \mathrm{s} / \mathrm{cm}^{2} / \mathrm{sr}\right)$} \\
\hline & Week 1 & Week 2 & Week 3 & Week 4 \\
\hline MNNG/HOS-luc ${ }^{+}(n=8)$ & $34,116 \pm 15,252$ & $154,657 \pm 31,389$ & $2,228,340 \pm 424,765$ & $3,300,566 \pm 181,221$ \\
\hline $143 \mathrm{~B}-\operatorname{luc}^{+}(n=5)$ & ND & $2,430 \pm 212$ & $69,208 \pm 23,122$ & $71,006 \pm 23,650$ \\
\hline
\end{tabular}

$\mathrm{p} / \mathrm{s} / \mathrm{cm}^{2} / \mathrm{sr}$ photons per second per square centimetre per steradian, $N D$ not detected 

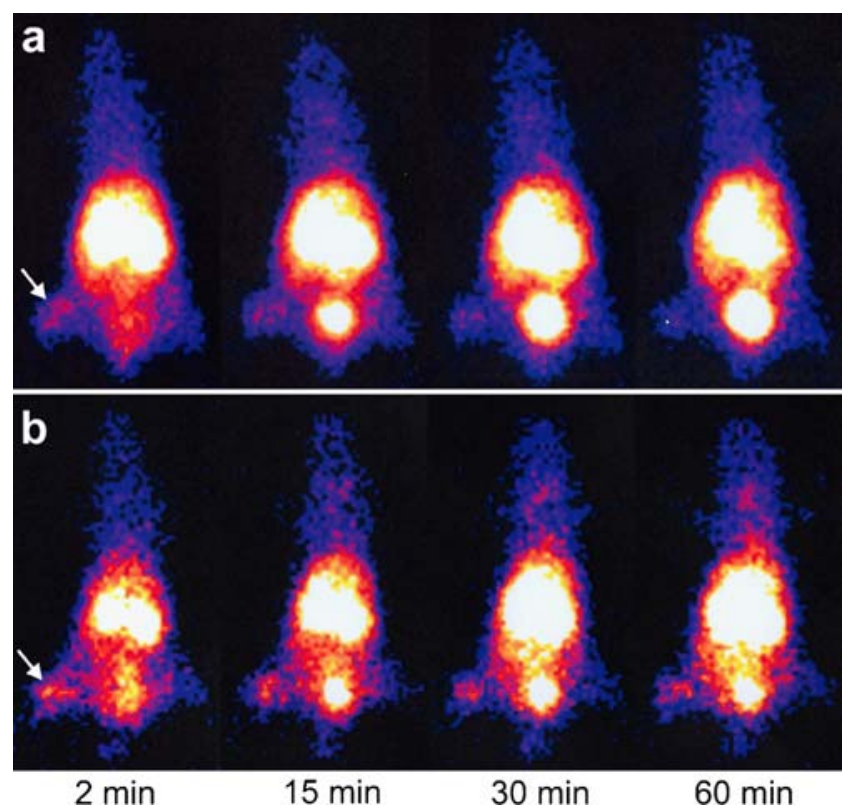

Fig. 2 Representative ${ }^{99 \mathrm{~m}} \mathrm{Tc}$-sestamibi dynamic images of mice bearing orthotopic 143B-luc ${ }^{+}$tumours in the right tibiae. Animals were imaged at 4 weeks after tumour cell inoculation, without PSC833 (a) and after treatment with $50 \mathrm{mg} / \mathrm{kg}$ PSC833 (b)

The percentage washout rate (\%WR) was significantly higher in MNNG/HOS-luc ${ }^{+}$than in 143B-luc ${ }^{+}$tumours $(37.5 \% \pm 4.0 \%$ vs $24.6 \% \pm 7.5 \%, p<0.05)$. PSC 833 decreased significantly the $\% \mathrm{WR}$ in MNNG/HOS-luc ${ }^{+}$tumours $(\%$ $\mathrm{WR}=21.7 \% \pm 2.5 \%, p<0.05)$ and had no significant effects on $143 \mathrm{~B}-\mathrm{luc}^{+}$tumours $(\% \mathrm{WR}=19.4 \% \pm 1.9 \%, p>0.05)$ (Table 2).
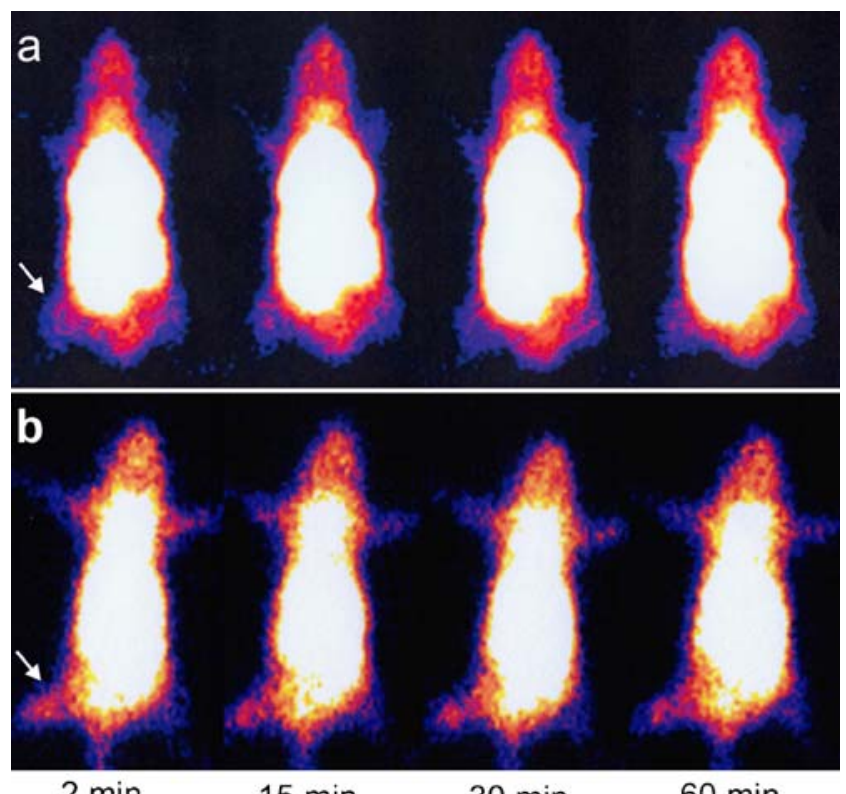

$$
2 \mathrm{~min} \quad 15 \mathrm{~min} \quad 30 \mathrm{~min} \quad 60 \mathrm{~min}
$$

Fig. 3 Representative ${ }^{99 m}$ Tc-sestamibi dynamic images of mice bearing orthotopic MNNG/HOS-luc ${ }^{+}$tumours in the right tibiae. Animals were imaged at 4 weeks after tumour cell inoculation, without PSC833 (a) and after treatment with $50 \mathrm{mg} / \mathrm{kg}$ PSC833 (b)
The T/NT ratios of ${ }^{99 \mathrm{~m}} \mathrm{Tc}$-sestamibi on early ( $5 \mathrm{~min}$ ) and delayed $(60 \mathrm{~min})$ images were significantly $(p<0.05)$ higher in $143 \mathrm{~B}-\mathrm{luc}^{+}$tumours $(2.14 \pm 0.36$ and $1.62 \pm 0.33$, respectively) than in MNNG/HOS-luc ${ }^{+}$tumours $(1.55 \pm 0.22$ and $1.12 \pm 0.11$, respectively) (Table 2). PSC 833 had no significant effects on either early or delayed T/NT ratios in 143B-luc ${ }^{+}$tumours. Although administrations of PSC 833 increased the T/NT ratios in MNNG/HOS-luc ${ }^{+}$tumours, the differences were not statistically significant $(p>0.05)$.

Biodistribution data

The imaging results were confirmed by biodistribution analysis in tumours and organ samples (Table 3 ) at $2 \mathrm{~h}$ after ${ }^{99 \mathrm{~m}} \mathrm{Tc}$-sestamibi injection. The Pgp-expressing MNNG/ HOS-luc ${ }^{+}$tumours accumulated significantly less ${ }^{99 \mathrm{~m}} \mathrm{Tc}-$ sestamibi compared with the $143 \mathrm{~B}-\mathrm{luc}^{+}$tumours $(\% \mathrm{ID} /$ $\mathrm{g}=0.87 \pm 0.21$ vs $1.79 \pm 0.82, p<0.05)$. Treatment with PSC 833 increased significantly $(p<0.05)$ the accumulation of ${ }^{99 \mathrm{~m}} \mathrm{Tc}$-sestamibi in MNNG/HOS-luc ${ }^{+}(\% \mathrm{ID} / \mathrm{g}=1.32 \pm$ $0.31)$ tumours and had no significant effect in 143B-luc ${ }^{+}$ tumours $(\% \mathrm{ID} / \mathrm{g}=2.27 \pm 0.42, p>0.05) .{ }^{99 \mathrm{~m}} \mathrm{Tc}$-sestamibi whole-body distribution showed normal physiological values with highest accumulation in the heart, liver and kidney, and did not differ significantly between mice bearing 143B-luc ${ }^{+}$or MNNG/HOS-luc ${ }^{+}$tumours. No significant differences were observed after treatment with PSC833.

\section{Discussion}

This study was designed to assess the ability of ${ }^{99 \mathrm{~m}} \mathrm{Tc}$ sestamibi imaging to detect Pgp-mediated multidrug resistance in OS. For that purpose we developed a clinically relevant animal model of OS by orthotopic injection of human OS cells in mice. Tumour growth and progression were monitored using BLI and conventional radiology techniques. Two established human OS cell lines (143B, MNNG/HOS) with different chemosensitivity to doxorubicin and expressing different levels of Pgp were successfully transfected with firefly luciferase and inoculated directly into the proximal tibia of nude mice.

The orthotopic inoculation of tumour cells promoted the development of local intratibial tumours. The high sensitivity of BLI permitted the continuous monitoring of tumour progression from the early stages of development (1-2 weeks) to the time of ${ }^{99 \mathrm{~m}} \mathrm{Tc}$-sestamibi imaging (4 weeks). In contrast to BLI, conventional radiography was only useful in the later stages of tumour development (3-4 weeks), when the first signs of osteolytic lesions became evident. Moreover, osteolysis is an indirect, late and inconsistent 
Fig. 4 Time-activity curves of ${ }^{99 \mathrm{~m}} \mathrm{Tc}$-sestamibi in 143B-luc ${ }^{+}$ (a) and MNNG/HOS-luc ${ }^{+}$(b) tumours in the absence ( $\mathbf{a})$ and in the presence ( $\square$ ) of PSC833. The radioactivity over the tumour area was normalised to the maximum activity obtained $2-3$ min post-injection and corrected for physical decay a $143 \mathrm{~B}_{\text {-luc }}^{+}$tumours

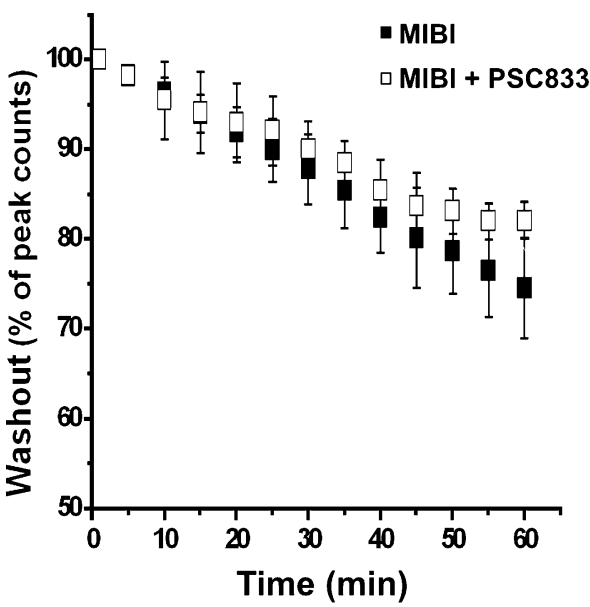

b MNNG/HOS-luc ${ }^{+}$tumours

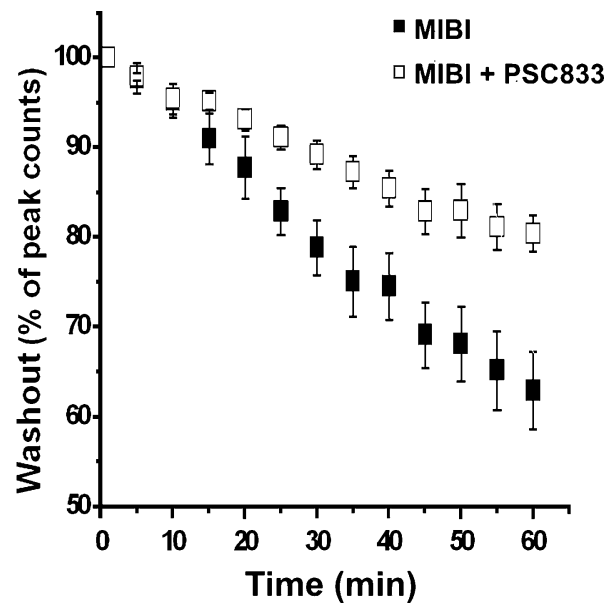

sign of tumour progression and does not take into account the extension into the surrounding soft tissues.

Several factors can account for the differences observed in the intensity and progression of bioluminescent signal between the MNNG/HOS-luc ${ }^{+}$and 143B-luc ${ }^{+}$tumours. The 143B cell line was transfected under the control of the CMV promoter; whereas MNNG/HOS was transfected under control of $\mathrm{EF} 1 \alpha$, since the CMV promoter did not result in detectable luciferase activity in MNNG/HOS. The activity of the CMV promoter depends on the cell cycle stage and medium composition [41]. It was shown that changes in the CMV promoter activity, induced by DNA methylation and histone deacetylation, can silence the gene expression and decrease the signal intensity during in vivo imaging [42]. Moreover, the bioluminescence emission requires the presence of D-luciferin in tumour cells. This substrate is oxidised by luciferase in the presence of cofactors (oxygen, adenosine triphosphate and magnesium). Inefficient cell uptake of D-luciferin due to alterations in tumour blood supply and cell membrane permeability decreases the luciferase activity. Scatena et al. [43] also observed constant bioluminescent signals in prostate tumours despite the 3.3-fold increase in tumour volume. This indicates that luciferase expression can be lost in time, probably owing to genomic instability.

Additionally, although the recorded bioluminescent intensity depends linearly on the proliferation of luciferase-expressing cells, it also has a strong non-linear dependence on tumour depth owing to attenuation and scattering of emitted light by overlying tissues and tumour optical properties $[30,44]$. This is an inherent feature of this imaging modality. Therefore, the intensity of the bioluminescent signal may not always be taken as a direct measure of cell proliferation.

To date, most in vivo studies on MDR have been performed in experimental models with subcutaneous tumours. In these models, tumour cells are selected in vitro for the MDR phenotype by exposure to anticancer drugs and then injected subcutaneously in the back or flank of nude mice. Although these models are adequate for specific assays, such as the rapid screening of new compounds, they cannot reproduce the physiological environment, which

Table 2 Effects of PSC833 on ${ }^{99 \mathrm{~m}} \mathrm{Tc}$-sestamibi kinetic parameters in $143 \mathrm{~B}-\mathrm{luc}^{+}$and MNNG/HOS-luc ${ }^{+}$tumours

\begin{tabular}{|c|c|c|c|c|}
\hline \multirow[t]{2}{*}{ Parameter } & \multicolumn{2}{|l|}{ 143B-luc ${ }^{+}$} & \multicolumn{2}{|c|}{ MNNG/HOS-luc ${ }^{+}$} \\
\hline & MIBI & MIBI+PSC833 & MIBI & MIBI+PSC 833 \\
\hline$t_{1 / 2}(\min )$ & $161.0 \pm 47.4$ & $195.2 \pm 21.0$ & $87.3 \pm 15.7^{*}$ & $173.0 \pm 24.5^{* *}$ \\
\hline WR (\%) & $24.6 \pm 7.5$ & $19.4 \pm 1.9$ & $37.5 \pm 4.0^{*}$ & $21.7 \pm 2.5^{* *}$ \\
\hline $\mathrm{T} / \mathrm{NT}_{5} \min$ & $2.14 \pm 0.36$ & $2.07 \pm 1.10$ & $1.55 \pm 0.22 *$ & $2.33 \pm 0.70$ \\
\hline $\mathrm{T} / \mathrm{NT}_{60} \min$ & $1.62 \pm 0.33$ & $1.67 \pm 0.84$ & $1.12 \pm 0.11^{*}$ & $1.85 \pm 0.64$ \\
\hline
\end{tabular}

Results are expressed as mean $\pm \mathrm{SD}$ of at least four mice

$M I B I{ }^{99 \mathrm{~m}} \mathrm{Tc}$-sestamibi, $t_{1 / 2}$ washout half-time, WR (\%) percentage washout rate, $T / N T_{5}$ min tumour/non-tumour ratio at $5 \mathrm{~min}, T / N T_{60} \mathrm{~min}$ tumour/ non-tumour ratio at $60 \mathrm{~min}$

${ }^{*} p<0.05$ compared with 143B-luc ${ }^{+}$tumours without PSC833

$*^{* *} p<0.05$ compared with MNNG/HOS-luc ${ }^{+}$tumours without PSC833 
Table 3 Biodistribution data (\%ID/g) of ${ }^{99 \mathrm{~m}}$ Tc-sestamibi in tumour-bearing nude mice at $2 \mathrm{~h}$ after infection

\begin{tabular}{lllll}
\hline Organ & \multicolumn{2}{l}{$143 \mathrm{~B}-\mathrm{luc}^{+}$} & & \multicolumn{2}{l}{ MNNG/HOS-luc } \\
\cline { 2 - 3 } & MIBI & MIBI+PSC833 & MIBI & MIBI+PSC833 \\
\hline Blood & $0.13 \pm 0.04$ & $0.18 \pm 0.06$ & $0.19 \pm 0.07$ & $0.21 \pm 0.05$ \\
Heart & $20.84 \pm 6.67$ & $23.94 \pm 4.87$ & $24.65 \pm 7.54$ & $26.87 \pm 5.86$ \\
Lung & $3.03 \pm 1.01$ & $3.61 \pm 1.79$ & $5.03 \pm 2.81$ & $13.02 \pm 2.06$ \\
Liver & $10.12 \pm 3.47$ & $12.14 \pm 6.94$ & $22.79 \pm 9.42$ & $16.39 \pm 1.56$ \\
Kidney & $22.47 \pm 7.78$ & $27.69 \pm 12.79$ & $0.54 \pm 0.27$ & $24.89 \pm 11.22$ \\
Normal tibia & $0.22 \pm 0.15$ & $0.52 \pm 0.35$ & $1.19 \pm 0.68$ & $1.57 \pm 0.29$ \\
Muscle & $1.54 \pm 0.62$ & $2.01 \pm 0.42$ & $0.87 \pm 0.21^{*}$ & $1.32 \pm 0.31^{* *}$ \\
Tumour & $1.79 \pm 0.82$ & $2.27 \pm 0.42$ & & \\
\hline
\end{tabular}

Data are presented as mean $\pm \mathrm{SD}$ of at least four experiments

$M I B I^{99 \mathrm{~m}}$ Tc-sestamibi

${ }^{*} p<0.05$ compared with $143 \mathrm{~B}-\mathrm{luc}^{+}$tumours without PSC833

$* * p<0.05$ compared with MNNG/HOS-luc ${ }^{+}$tumours without PSC833

influences the biological behaviour of tumour cells. In fact, Dong et al. [45] demonstrated that the organ environment influences the Pgp expression in colon carcinoma cells, affecting their in vivo sensitivity to doxorubicin. The Pgp gene expression depends on a variety of host factors such as interaction with the extracellular matrix and environmental mitogenic signals $[46,47]$. This fact underlines the critical role of the specific organ microenvironment on tumour development and gene expression. To our knowledge this is the first application of an orthotopic model of OS for molecular imaging of MDR using radiotracers. Moreover, we used human OS cell lines not previously selected for drug resistance, a condition closer to the clinical setting.

The results we obtained suggest that differences in Pgp expression in OS can be detected non-invasively by scintigraphic imaging with ${ }^{99 \mathrm{~m}} \mathrm{Tc}$-sestamibi. In our study, a 1-h tracer kinetic analysis detected a faster washout rate of ${ }^{99 \mathrm{~m}} \mathrm{Tc}$-sestamibi in the MNNG/HOS-luc ${ }^{+}$tumours when compared with the 143B-luc ${ }^{+}$tumours. T/NT ratios on both early $(5 \mathrm{~min})$ and delayed $(60 \mathrm{~min})$ images were also significantly reduced in MNNG/HOS-luc ${ }^{+}$cells when compared with 143B-luc ${ }^{+}$tumours. These findings are largely consistent with our previous results from in vitro studies in the same cell lines, indicating that the reduced uptake and the faster washout rate of ${ }^{99 \mathrm{~m}} \mathrm{Tc}$-sestamibi are associated with higher expression of Pgp in the MNNG/ HOS cell line [28]. This conclusion is strengthened by the fact that the pharmacological inhibition of Pgp using a specific inhibitor (PSC833) led to a significant decrease in the ${ }^{99 \mathrm{~m}} \mathrm{Tc}$-sestamibi efflux rate in Pgp-expressing tumours (MNNG/HOS-luc ${ }^{+}$).

The clinical relevance of ${ }^{99 \mathrm{~m}} \mathrm{Tc}$-sestamibi in predicting chemotherapy response has been investigated in several tumours. Some authors have reported an inverse correlation between tumour-to-background ratio, usually measured at delayed times, and Pgp expression in tumours [22, 48, 49].
Other reports suggest that enhanced tracer clearance is an index of Pgp function and might predict Pgp-mediated resistance to chemotherapy and treatment failure [21, 24, $50,51]$. Our results indicate that both uptake and washoutrelated parameters discriminate these tumours based on differential expression levels of Pgp. However, the washout half-time appears to be a better predictor of drug resistance, as it results in a twofold difference between MNNG/HOS$\mathrm{luc}^{+}$and 143B-luc ${ }^{+}$, as compared with the 1.4-fold difference observed for T/NT (early and delayed) ratios and $\% \mathrm{WR}$. Moreover, the washout half-life appears to be a more reliable index than \%WR, which is subjected to higher variability depending on the delayed imaging time.

Despite our encouraging results, the prognostic value of ${ }^{99 \mathrm{~m}} \mathrm{Tc}$-sestamibi uptake for tumour response should be carefully evaluated. The absence or reduction of ${ }^{99 \mathrm{~m}} \mathrm{Tc}$ sestamibi uptake on early images may suggest that ${ }^{99 \mathrm{~m}} \mathrm{Tc}$ sestamibi uptake can also be influenced by other factors, rather than simply Pgp activity. Inefficient blood supply, advanced cell necrosis, hypoxia and the overexpression of the apoptotic protein Bcl-2 may significantly reduce the uptake of ${ }^{99 \mathrm{~m}} \mathrm{Tc}$-sestamibi in tumour lesions [52]. Aloj et al. [53] found a significant correlation between the absence of ${ }^{99 \mathrm{~m}} \mathrm{Tc}$-sestamibi uptake and overexpression of $\mathrm{Bcl}-2$ in breast cancer cell lines. Multidrug resistance-associated protein 1 (MRP1) can also be overexpressed in tumour cells, conferring drug resistance $[23,54]$. Decreased uptake or enhanced efflux of ${ }^{99 \mathrm{~m}} \mathrm{Tc}$-sestamibi can be mediated by MRP1 [19, 23]. In this model, the hypothesis of MRP1mediated outward transport of ${ }^{99 \mathrm{~m}} \mathrm{Tc}$-sestamibi is excluded since our previous studies found that MRP1 is equally expressed in 143B and MNNG/HOS cell lines [28].

In the present study we also showed that the outward transport of ${ }^{99 \mathrm{~m}} \mathrm{Tc}$-sestamibi in Pgp-expressing tumours can be reduced by pre-treatment with PSC833, a potent Pgp inhibitor. PSC833 increased significantly the washout half-life and 
decreased the washout rate in $\mathrm{MNNG} / \mathrm{HOS}-\mathrm{luc}^{+}$tumours to values comparable to those observed in $143 \mathrm{~B}-$ luc $^{+}$tumours. Interestingly, no significant increase was observed in $\mathrm{T} / \mathrm{NT}$ ratios for $\mathrm{MNNG} \mathrm{HOS}-\mathrm{luc}^{+}$tumours after treatment with PSC833. This indicates that the T/NT ratio is not a consistent index for evaluation of the inhibitor effects of PSC833 on Pgp transport activity. As mentioned above, uptake is influenced by multiple factors other than Pgp expression. Additionally, Pgp is expressed in several normal tissues, including muscle tissue. As inhibition of Pgp may occur in normal tissue, the PSC833 action affects simultaneously the two factors used to calculate T/NT ratios, making this index less sensitive to the inhibition of Pgp in tumours. The biodistribution data at 2 $\mathrm{h}$ after injection support this hypothesis. In fact, administration of PSC833 produced an increase in ${ }^{99 \mathrm{~m}} \mathrm{Tc}$-sestamibi accumulation in MNNG/HOS-luc ${ }^{+}$tumours (1.5-fold) and in muscle tissue (1.3-fold). As expected, administration of PSC833 had no significant effects on the washout half-life or $\% \mathrm{WR}$ or on T/NT ratios in 143B-luc ${ }^{+}$tumours. ${ }^{99 m}$ Tc-sestamibi biodistribution in $143 \mathrm{~B}-\mathrm{luc}^{+}$confirmed these results.

Clinical studies published on the prognostic value of ${ }^{99 m}$ Tc-sestamibi in OS have been few and apparently contradictory [23-25]. The different methodologies used for assessing Pgp expression/function, together with the small number of patients studied, might explain the discrepancies. Some researchers have suggested that Pgp expression measured at diagnosis in high-grade OS should be used as the basis for stratification therapy [55]. Our results are encouraging and demonstrate the potential of ${ }^{99 \mathrm{~m}}$ Tc-sestamibi imaging in predicting tumour response and monitoring the efficiency of MDR inhibitors in OS. However, further clinical and pre-clinical studies are needed for standardisation of imaging procedures and identification of reliable and direct indexes of Pgp functional activity in the clinical setting.

In conclusion, the orthotopic injection of cancer cells provides a xenograft model of human OS that can be used for functional imaging of MDR. Bioluminescence imaging allows the continuous sensitive non-invasive monitoring of tumour growth and progression. ${ }^{99 \mathrm{~m}} \mathrm{Tc}$-sestamibi imaging kinetics provides valuable information on the functional activity of Pgp expression and its pharmacological inhibition. This information could prove a very valuable tool in the clinical setting both for its prognostic value and in the planning of alternative therapeutic strategies in the clinical management of poor responders in OS.

Acknowledgements The authors thank Novartis Pharma (Basel, Switzerland) for kindly providing PSC833 and R.I.J. Feitsma (Department of Radiology, Section of Nuclear Medicine) for preparation of the radiopharmaceutical. The Department of Pathology, Leiden University Medical Center is a partner of EuroBoNeT, an ECKP6 granted network of excellence for study of pathology and genetics of bone tumours.
This research was supported in part by a grant from FARMA APS, Portugal.

\section{References}

1. Rosen G, Caparros B, Huvos AG, Kosloff C, Nirenberg A, Cacavio A, et al. Preoperative chemotherapy for osteogenic sarcoma: selection of postoperative adjuvant chemotherapy based on the response of the primary tumor to preoperative chemotherapy. Cancer 1982;49:1221-30.

2. Meyers PA, Heller G, Healey J, Huvos A, Lane J, Marcove R, et al. Chemotherapy for nonmetastatic osteogenic sarcoma: the Memorial Sloan-Kettering experience. J Clin Oncol 1992;10:5-15.

3. Provisor AJ, Ettinger LJ, Nachman JB, Krailo MD, Makley JT, Yunis EJ, et al. Treatment of nonmetastatic osteosarcoma of the extremity with preoperative and postoperative chemotherapy: a report from the Children's Cancer Group. J Clin Oncol 1997; 15:76-84.

4. Bielack SS, Kempf-Bielack B, Delling G, Exner GU, Flege S, Helmke K, et al. Prognostic factors in high-grade osteosarcoma of the extremities or trunk: an analysis of 1,702 patients treated on neoadjuvant cooperative osteosarcoma study group protocols. J Clin Oncol 2002;20:776-90.

5. Meyers PA, Gorlick R, Heller G, Casper E, Lane J, Huvos AG, et al. Intensification of preoperative chemotherapy for osteogenic sarcoma: results of the Memorial Sloan-Kettering (T12) protocol. J Clin Oncol 1998;16:2452-8.

6. Bacci G, Forni C, Ferrari S, Longhi A, Bertoni F, Mercuri M, et al. Neoadjuvant chemotherapy for osteosarcoma of the extremity: intensification of preoperative treatment does not increase the rate of good histologic response to the primary tumor or improve the final outcome. J Pediatr Hematol Oncol 2003;25:845-53.

7. Smeland S, Muller C, Alvegard TA, Wiklund T, Wiebe T, Bjork O, et al. Scandinavian Sarcoma Group Osteosarcoma Study SSG VIII: prognostic factors for outcome and the role of replacement salvage chemotherapy for poor histological responders. Eur J Cancer 2003;39:488-94.

8. Lewis IJ, Nooij MA, Whelan J, Sydes MR, Grimer R, Hogendoorn PC, et al. Improvement in histologic response but not survival in osteosarcoma patients treated with intensified chemotherapy: a randomized phase III trial of the European Osteosarcoma Intergroup. J Natl Cancer Inst 2007;99:112-28.

9. Borst P, Elferink RO. Mammalian ABC transporters in health and disease. Annu Rev Biochem 2002;71:537-92.

10. Gottesman MM, Fojo T, Bates SE. Multidrug resistance in cancer: role of ATP-dependent transporters. Nat Rev Cancer 2002;2:48-58.

11. Gottesman MM. Mechanisms of cancer drug resistance. Annu Rev Med 2002;53:615-27.

12. Baldini N, Scotlandi K, Barbantibrodano G, Manara MC, Maurici D, Bacci G, et al. Expression of P-glycoprotein in high-grade osteosarcomas in relation to clinical outcome. $\mathrm{N}$ Engl J Med 1995;333:1380-5.

13. Bodey B, Taylor CR, Siegel SE, Kaiser HE. Immunocytochemical observation of multidrug resistance (MDR) p170 glycoprotein expression in human osteosarcoma cells. The clinical significance of MDR protein overexpression. Anticancer Res 1995;15:2461-8.

14. Chan HS, Grogan TM, Haddad G, DeBoer G, Ling V. Pglycoprotein expression: critical determinant in the response to osteosarcoma chemotherapy. J Natl Cancer Inst 1997;89:1706-15.

15. Wunder JS, Bull SB, Aneliunas V, Lee PD, Davis AM, Beauchamp $\mathrm{CP}$, et al. MDR1 gene expression and outcome in osteosarcoma: a prospective, multicenter study. J Clin Oncol 2000;18:2685-94. 
16. Shnyder SD, Hayes AJ, Pringle J, Archer CW. P-glycoprotein and metallothionein expression and resistance to chemotherapy in osteosarcoma. Br J Cancer 1998;78:757-9.

17. Hendrikse NH, Franssen EJF, van der Graaf WTA, Vaalburg W, de Vries EGE. Visualization of multidrug resistance in vivo. Eur $\mathbf{J}$ Nucl Med 1999;26:283-93.

18. Ballinger JR, Hua HA, Berry BW, Firby P,Boxen I. ${ }^{99 \mathrm{~m}} \mathrm{Tc}-$ sestamibi as an agent for imaging P-glycoprotein-mediated multidrug resistance: in vitro and in vivo studies in a rat breast tumour cell line and its doxorubicin-resistant variant. Nucl Med Commun $1995 ; 16: 253-7$.

19. Utsunomiya K, Ballinger JR, Piquette-Miller M, Rauth AM, Tang $\mathrm{W}, \mathrm{Su} \mathrm{Z}-\mathrm{F}$, et al. Comparison of the accumulation and efflux kinetics of technetium- $99 \mathrm{~m}$ sestamibi and technetium- $99 \mathrm{~m}$ tetrofosmin in an MRP-expressing tumour cell line. Eur J Nucl Med 2000;27:1786-92.

20. Del Vecchio S, Ciarmiello A, Pace L, Potena MI, Carriero MV, Mainolfi C, et al. Fractional retention of technetium-99msestamibi as an index of P-glycoprotein expression in untreated breast cancer patients. J Nucl Med 1997;38:1348-51.

21. Kostakoglu L, Kiratli P, Ruacan S, Hayran M, Emri S, Ergun EL, et al. Association of tumor washout rates and accumulation of technetium-99 m-MIBI with expression of P-glycoprotein in lung cancer. J Nucl Med 1998;39:228-34.

22. Zhou J, Higashi K, Ueda Y, Kodama Y, Guo D, Jisaki F, et al. Expression of multidrug resistance protein and messenger RNA correlate with ${ }^{99 \mathrm{~m}} \mathrm{Tc}-\mathrm{MIBI}$ imaging in patients with lung cancer. J Nucl Med 2001;42:1476-83.

23. Burak Z, Moretti J, Ersoy O, Sanli U, Kantar M, Tamgac F, et al. ${ }^{99 \mathrm{~m}} \mathrm{Tc}-\mathrm{MIBI}$ Imaging as a predictor of therapy response in osteosarcoma compared with multidrug resistance-associated protein and P-glycoprotein expression. J Nucl Med 2003;44:1394 401.

24. Burak Z, Ersoy O, Moretti JL, Erinc R, Ozcan Z, Dirlik A, et al. The role of ${ }^{99 \mathrm{~m}} \mathrm{Tc}-\mathrm{MIBI}$ scintigraphy in the assessment of MDR1 overexpression in patients with musculoskeletal sarcomas: comparison with therapy response. Eur J Nucl Med 2001;28:1341-50.

25. Gorlick R, Liao AC, Antonescu C, Huvos AG, Healey JH, Sowers $\mathrm{R}$, et al. Lack of correlation of functional scintigraphy with $(99 \mathrm{~m})$ technetium-methoxyisobutylisonitrile with histological necrosis following induction chemotherapy or measures of P-glycoprotein expression in high-grade osteosarcoma. Clin Cancer Res 2001;7:3065-70.

26. Doyle LA, Ross DD. Multidrug resistance mediated by the breast cancer resistance protein BCRP (ABCG2). Oncogene 2003;22: $7340-58$.

27. Kruh GD, Belinsky MG. The MRP family of drug efflux pumps. Oncogene 2003;22:7537-52.

28. Gomes CMF, Paassen H, Romeo S, Welling MM, Feitsma RIJ, Abrunhosa $\mathrm{AJ}$, et al. Multidrug resistance mediated by $\mathrm{ABC}$ transporters in osteosarcoma cell lines assessed by mRNA analysis and functional radiotracer studies. Nucl Med Biol 2006;33:831-40. DOI 10.1016/j.nucmedbio.2006.07.011.

29. Berlin O, Samid D, Donthineni-Rao R, Akeson W, Amiel D, Woods VL Jr. Development of a novel spontaneous metastasis model of human osteosarcoma transplanted orthotopically into bone of athymic mice. Cancer Res 1993;53:4890-5.

30. Contag CH, Jenkins D, Contag PR, Negrin RS. Use of reporter genes for optical measurements of neoplastic disease in vivo. Neoplasia 2000;2:41-52.

31. Wetterwald A, van der Pluijm G, Que I, Sijmons B, Buijs J, Karperien M, et al. Optical imaging of cancer metastasis to bone marrow: a mouse model of minimal residual disease. Am J Pathol 2002;160:1143-53.

32. Luu HH, Kang Q, Park JK, Si W, Luo Q, Jiang W, et al. An orthotopic model of human osteosarcoma growth and spontaneous pulmonary metastasis. Clin Exp Metastasis 2005;22:319-29.
33. Nordeen SK. Luciferase reporter gene vectors for analysis of promoters and enhancers. Biotechniques 1988;6:454-8.

34. Cagliero E, Ferracini R, Morello E, Scotlandi K, Manara MC, Buracco $\mathrm{P}$, et al. Reversal of multidrug-resistance using Valspodar (PSC 833) and doxorubicin in osteosarcoma. Oncol Rep 2004;12:1023-31.

35. Chen CC, Meadows B, Regis J, Kalafsky G, Fojo T, Carrasquillo JA, et al. Detection of in vivo P-glycoprotein inhibition by PSC 833 using Tc-99m sestamibi. Clin Cancer Res 1997;3:545-52.

36. Barbarics E, Kronauge JF, Cohen D, Davison A, Jones AG, Croop JM. Characterization of P-glycoprotein transport and inhibition in vivo. Cancer Res 1998;58:276-82.

37. Liu Z, Stevenson GD, Barrett HH, Furenlid LR, Wilson DW, Kastis GA, et al. Imaging recognition of inhibition of multidrug resistance in human breast cancer xenografts using ${ }^{99 \mathrm{~m}} \mathrm{Tc}$-labeled sestamibi and tetrofosmin. Nucl Med Biol 2005;32:573-83.

38. Bates SE, Bakke S, Kang M, Robey RW, Zhai S, Thambi P, et al. A phase I/II study of infusional vinblastine with the P-glycoprotein antagonist valspodar (PSC 833) in renal cell carcinoma. Clin Cancer Res 2004;10:4724-33.

39. Friedenberg WR, Rue M, Blood EA, Dalton WS, Shustik C, Larson RA, et al. Phase III study of PSC-833 (valspodar) in combination with vincristine, doxorubicin, and dexamethasone (valspodar/VAD) versus VAD alone in patients with recurring or refractory multiple myeloma (E1A95): a trial of the Eastern Cooperative Oncology Group. Cancer 2006;106:830-8.

40. van der Pluijm G, Sijmons B, Vloedgraven H, Deckers M, Papapoulos S, Lowik C. Monitoring metastatic behavior of human tumor cells in mice with species-specific polymerase chain reaction: elevated expression of angiogenesis and bone resorption stimulators by breast cancer in bone metastases. J Bone Miner Res 2001;16:1077-91.

41. Brightwell G, Poirier V, Cole E, Ivins S, Brown KW. Serumdependent and cell cycle-dependent expression from a cytomegalovirus-based mammalian expression vector. Gene 1997;194:115-23.

42. Krishnan M, Park JM, Cao F, Wang D, Paulmurugan R, Tseng JR, et al. Effects of epigenetic modulation on reporter gene expression: implications for stem cell imaging. FASEB J 2006;20:106-8.

43. Scatena CD, Hepner MA, Oei YA, Dusich JM, Yu SF, Purchio T, et al. Imaging of bioluminescent LNCaP-luc-M6 tumors: a new animal model for the study of metastatic human prostate cancer. Prostate 2004;59:292-3.

44. El Hilali N, Rubio N, Martinez-Villacampa M, Blanco J. Combined noninvasive imaging and luminometric quantification of luciferase-labeled human prostate tumors and metastases. Lab Invest 2002;82:1563-71.

45. Dong Z, Radinsky R, Fan D, Tsan R, Bucana CD, Wilmanns C, et al. Organ-specific modulation of steady-state mdr gene expression and drug resistance in murine colon cancer cells. J Natl Cancer Inst 1994;86:913-20.

46. Schuetz JD, Schuetz EG. Extracellular matrix regulation of multidrug resistance in primary monolayer cultures of adult rat hepatocytes. Cell Growth Differ 1993;4:31-40.

47. Radinsky R. Modulation of tumor cell gene expression and phenotype by the organ-specific metastatic environment. Cancer Metastasis Rev 1995;14:323-38.

48. Kostakoglu L, Elahi N, Kiratli P, Ruacan S, Sayek I, Baltati E, et al. Clinical validation of the influence of P-glycoprotein and technetium-99 m-sestamibi uptake in malignant tumors. J Nucl Med 1997;38:1003-8.

49. Moretti JL, Azaloux H, Boisseron D, Kouyoumdjian JC, Vilcoq J. Primary breast cancer imaging with technetium- $99 \mathrm{~m}$ sestamibi and its relation with P-glycoprotein overexpression. Eur J Nucl Med 1996;23:980-6.

50. Sciuto R, Pasqualoni R, Bergomi S, Petrilli G, Vici P, Belli F, et al. Prognostic value of ${ }^{99 \mathrm{~m}} \mathrm{Tc}$-sestamibi washout in predicting 
response of locally advanced breast cancer to neoadjuvant chemotherapy. J Nucl Med 2002;43:745-51.

51. Del Vecchio S, Ciarmiello A, Potena MI, Carriero MV, Mainolfi $\mathrm{C}$, Botti $\mathrm{G}$, et al. In vivo detection of multidrug-resistant (MDR1) phenotype by technetium-99m sestamibi scan in untreated breast cancer patients. Eur J Nucl Med 1997;24:150-9.

52. Moretti JL, Hauet N, Caglar M, Rebillard O, Burak Z. To use MIBI or not to use MIBI? That is the question when assessing tumour cells. Eur J Nucl Med Mol Imaging 2005;32:836-42.
53. Aloj L, Zannetti A, Caraco C, Del Vecchio S, Salvatore M. Bcl-2 overexpression prevents ${ }^{99 \mathrm{~m}} \mathrm{Tc}-\mathrm{MIBI}$ uptake in breast cancer cell lines. Eur J Nucl Med Mol Imaging 2004;31:521-7.

54. Bruheim S, Bruland OS, Breistol K, Maelandsmo GM, Fodstad O. Human osteosarcoma xenografts and their sensitivity to chemotherapy. Pathol Oncol Res 2004;10:133-41.

55. Baldini N, Scotlandi K, Serra M, Picci P, Bacci G, Sottili S, et al. P-glycoprotein expression in osteosarcoma: a basis for riskadapted adjuvant chemotherapy. J Orthop Res 1999;17:629-32. 